\title{
Article
}

\section{Xyloglucan Remodeling Defines Auxin-Dependent Differential Tissue Expansion in Plants}

\author{
Silvia Melina Velasquez ${ }^{1, *}$, Xiaoyuan Guo ${ }^{2,+}$, Marçal Gallemi ${ }^{3,+}{ }^{+}$Bibek Aryal ${ }^{4, \dagger}{ }^{\dagger}$, Peter Venhuizen ${ }^{1}$ (1),

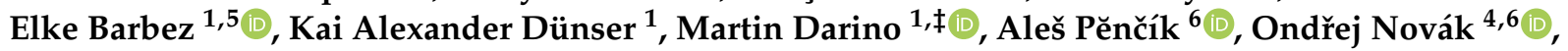 \\ Maria Kalyna ${ }^{1} \mathbb{D}$, Gregory Mouille ${ }^{7}$, Eva Benková ${ }^{3}$, Rishikesh P. Bhalerao ${ }^{4}$, Jozef Mravec ${ }^{2}$ \\ and Jürgen Kleine-Vehn ${ }^{5,8, *(\mathbb{C})}$
}

check for updates

Citation: Velasquez, S.M.; Guo, X.; Gallemi, M.; Aryal, B.; Venhuizen, P.; Barbez, E.; Dünser, K.A.; Darino, M.; Pěnčík, A.; Novák, O.; et al. Xyloglucan Remodeling Defines Auxin-Dependent Differential Tissue Expansion in Plants. Int. J. Mol. Sci. 2021, 22, 9222. https://doi.org/ $10.3390 /$ ijms 22179222

Academic Editor: Kamil Růžička

Received: 6 August 2021

Accepted: 24 August 2021

Published: 26 August 2021

Publisher's Note: MDPI stays neutral with regard to jurisdictional claims in published maps and institutional affiliations.

Copyright: (c) 2021 by the authors. Licensee MDPI, Basel, Switzerland. This article is an open access article distributed under the terms and conditions of the Creative Commons Attribution (CC BY) license (https:/ / creativecommons.org/licenses/by/ $4.0 /)$.
1 Department of Applied Genetics and Cell Biology, University of Natural Resources and Life Sciences Vienna (BOKU), Muthgasse 18, 1190 Vienna, Austria; peter.venhuizen@boku.ac.at (P.V.); elkebarbez@gmail.com (E.B.); kai.duenser@boku.ac.at (K.A.D.); martin.a.darino@gmail.com (M.D.); mariya.kalyna@boku.ac.at (M.K.)

2 Department of Plant and Environmental Sciences, University of Copenhagen, Thorvaldsensvej 40, DK-1871 Frederiksberg C, Denmark; yuanquane@gmail.com (X.G.); mravec@plen.ku.dk (J.M.)

3 Institute of Science and Technology Austria, 3400 Klosterneuburg, Austria; marcal.gallemi@ist.ac.at (M.G.); eva.benkova@ist.ac.at (E.B.)

4 Department of Forest Genetics and Plant Physiology, Umeå Plant Science Centre, Swedish University of Agricultural Sciences, SE-901 87 Umeå, Sweden; Bibek.aryal@slu.se (B.A.); ondrej.novak@upol.cz (O.N.); Rishi.Bhalerao@slu.se (R.P.B.)

5 Faculty of Biology, Department of Molecular Plant Physiology (MoPP), University of Freiburg, 79104 Freiburg, Germany

6 Laboratory of Growth Regulators, Faculty of Science, Palacký University and Institute of Experimental Botany, The Czech Academy of Sciences, Šlechtitelů 27, 78371 Olomouc, Czech Republic; alespencik@seznam.cz

7 Institut Jean-Pierre Bourgin, Institut National de la Recherche Agronomique, AgroParisTech, CNRS, Université Paris-Saclay, RD10, CEDEX, 78026 Versailles, France; gregory.mouille@inra.fr

8 Center for Integrative Biological Signalling Studies (CIBSS), University of Freiburg, 79104 Freiburg, Germany

* Correspondence: melina.velasquez@gmail.com (S.M.V.); juergen.kleine-vehn@biologie.uni-freiburg.de (J.K.-V.)

+ Equal contributions.

$\ddagger$ Current Address: Molecular Plant Pathology, Department of Biointeractions and Crop Protection, Rothamsted Research, Harpenden, Hertfordshire AL5 2JQ, UK.

\begin{abstract}
Size control is a fundamental question in biology, showing incremental complexity in plants, whose cells possess a rigid cell wall. The phytohormone auxin is a vital growth regulator with central importance for differential growth control. Our results indicate that auxin-reliant growth programs affect the molecular complexity of xyloglucans, the major type of cell wall hemicellulose in eudicots. Auxin-dependent induction and repression of growth coincide with reduced and enhanced molecular complexity of xyloglucans, respectively. In agreement with a proposed function in growth control, genetic interference with xyloglucan side decorations distinctly modulates auxin-dependent differential growth rates. Our work proposes that auxin-dependent growth programs have a spatially defined effect on xyloglucan's molecular structure, which in turn affects cell wall mechanics and specifies differential, gravitropic hypocotyl growth.
\end{abstract}

Keywords: auxin; growth; cell wall; xyloglucans; hypocotyls; gravitropism

\section{Introduction}

The phytohormone auxin is a central regulator of plant development and is of pivotal importance for differential growth control. Despite its significance, we do not fully understand the subcellular mechanisms by which auxin reliant growth programs define the size of a cell that is surrounded by a rigid cell wall structure. Auxin signaling steers promotion and repression of cell expansion in a concentration- and cell-type-dependent 
manner [1]. The cellular levels of auxin rely on a complex interplay between metabolism and intercellular transport [2-4]. On the other hand, tissue specific expression of auxin signaling components and intracellular auxin transport define cellular sensitivity to auxins [5-7]. Transcriptional auxin responses take place in the nucleus via auxin binding to its co-receptors transport inhibitor response 1/auxin signaling F-box (TIR1/AFBs) and the transcriptional repressor auxin/indole-3-acetic acid (Aux/IAAs) [8]. Auxin-induced cellular elongation in hypocotyls requires TIR1/AFBs-dependent transcriptional auxin responses [9]. In contrast, auxin-triggered repression of root cell expansion utilizes a TIR1/AFBs-dependent, non-genomic pathway [10]. In addition, the receptor like kinase TRANSMEMBRANE RECEPETOR LIKE KINASE1 (TMK1) is required for a non-genomic effect of auxin in apical hooks, repressing growth at the inner side (concave) [11]. On the other hand, TMK1 does not impact on hypocotyl expansion [12]. These findings suggest a complex and tissue specific interplay of auxin signaling and growth.

Auxin-dependent control of cellular expansion is in part manifested by stiffening or loosening of the primary cell wall [13], but the underlying molecular mechanisms remain long-standing research questions. The plant cell wall in eudicots is a complex composite structure comprised mainly of polysaccharides, such as cellulose microfibrils, branched xyloglucans $(\mathrm{XyG})$, arabinoxylans, mannans, a diverse pectin matrix and proteoglycans (extensins and arabinogalactan proteins) [14]. The extracellular XyG polymer is made of $\beta$-1,4-linked D-glucose with functional glycosyl side-chains. In Arabidopsis thaliana, typically $75 \%$ of the glucose units are substituted with a xylosyl residue, which can be further substituted either with galactose alone or a galactose moiety decorated with a fucose and/or an O-acetyl group (overview in Figure S1) [15,16]. The acid growth theory proposes that an auxin-dependent increase in plasma membrane proton pump activity triggers rapid cell wall acidification [17]. The decrease of extracellular $\mathrm{pH}$ initiates a cascade of events, including activation of expansins, which dissociate XyG-cellulose networks and consequently promote cell wall loosening $[18,19]$. However, the complexity of the cell wall and also the concentration- and tissue-dependent effects of auxin question the universal validity of a single growth mechanism (e.g., $[7,20])$.

Interestingly, a yet unknown cell wall sensing mechanism perceives defects in the cell wall mechanics, such as the loss of XyG synthesis, and provides an AUXIN RESPONSE FACTOR 2 (ARF2)-dependent negative feedback on intercellular auxin transport in apical hooks [21]. Conversely, several studies have shown that auxin signaling affects various XyG-related genes suggesting an effect of auxin signaling on XyG-related processes [22-30]. However, the contribution of such a potential interplay to differential growth remains unknown. Here we show that growth inducing and repressing conditions reduce and stimulate the molecular complexity of extracellular xyloglucans, respectively. Using genetic, biochemical and imaging approaches, we provide evidence that auxin-dependent growth programs exert a spatial control on $\mathrm{XyG}$ structure, namely on the level and types of backbone substitutions, which contributes to gravity induced, differential growth in dark grown hypocotyls.

\section{Results}

\subsection{Auxin-Induced Cell Expansion Correlates with Spatial Changes in the Structure of Xyloglucans in Pea and Arabidopsis}

In order to study auxin-reliant differential growth, we exposed plants to a gravitropic stimulus, which activates a complex sequence of events ultimately inducing an asymmetric increase of auxin and consequently cellular elongation at the lower side of the shoot [31]. We initially evaluated pea stems, because they provide material in quantities sufficient for immunoglycan profiling and are amendable to local auxin manipulation. We longitudinally dissected gravistimulated stems and separated the longer (more elongated, convex) and shorter (less elongated; concave) sides (Figure 1A). 
A

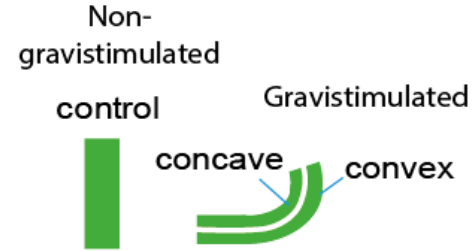

B

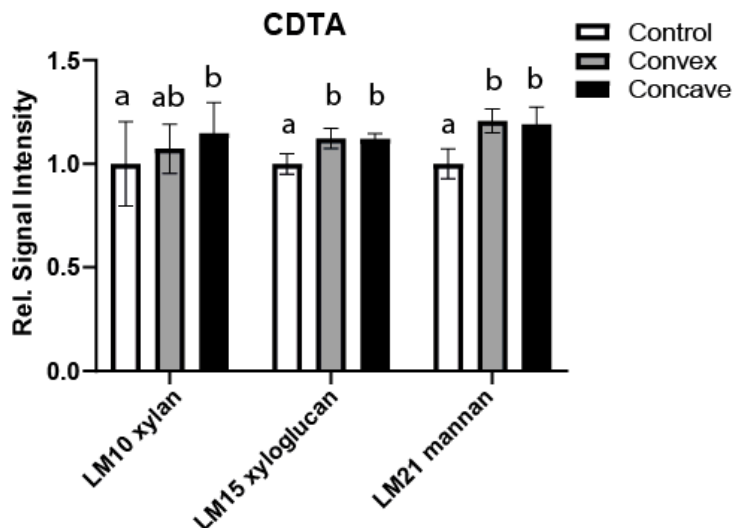

C

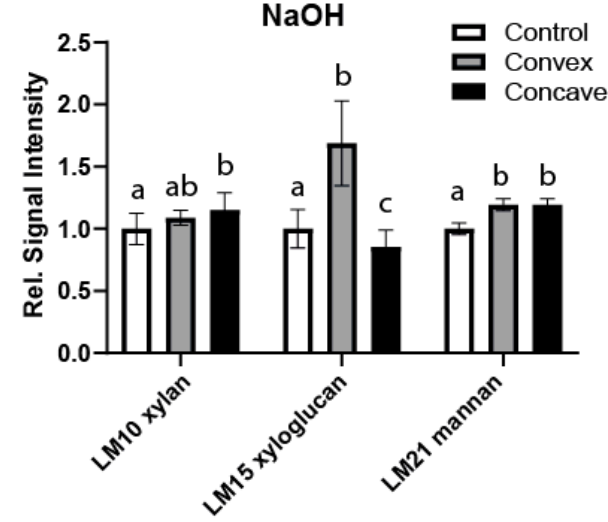

D

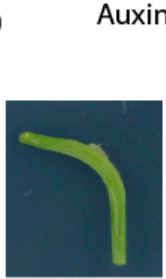

Auxin paste

Lanolin only (Control)

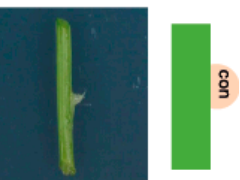

E

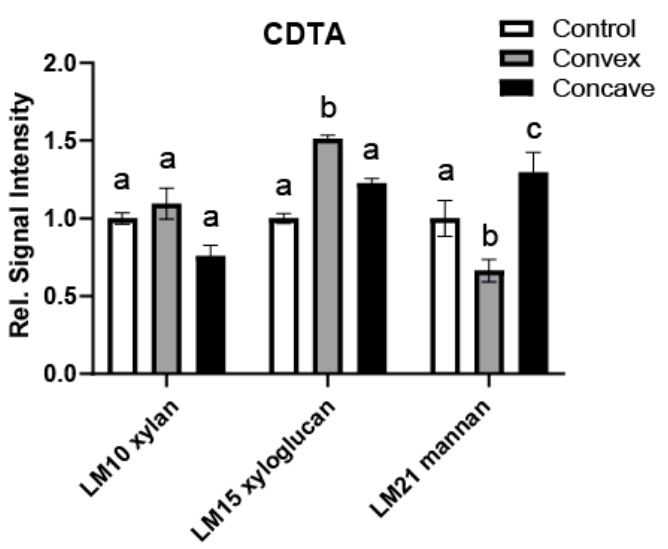

F

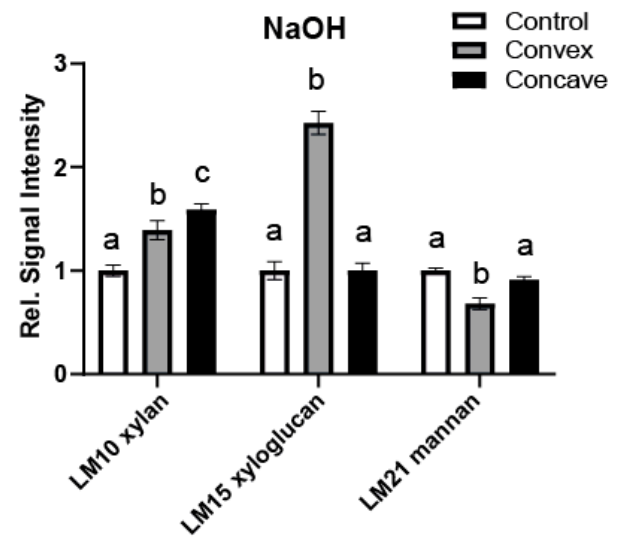

Figure 1. (A-C) Comprehensive Microarray Polymer Profiling (CoMPP) of differentially elongated stem segments after gravistimulation. The LM15 antibody, specific to the non-galactosylated (XXXG) motif of Xyloglucan (XyG), showed increased epitope detection in longer stem segments. (A) Schematic of the experimental design. (B,C) Quantification of relative changes in the signal intensities with a cyclohexanediaminetetraacetic acid (CDTA) (B) and $\mathrm{NaOH}(\mathbf{C})$ extraction in relation to non-stimulated control ( $n=10$ sectioned pairs, error bars represent SEM). Two-way ANOVA followed by Tukey's test with $p$-value $<0.05$. (D-F) CoMPP profiling of pea segments after three-day treatment with an indole-3-acetic acid (IAA)-containing lanolin paste. (D) Schematic representation of the auxin application assay. (E,F) Relative quantifications of both CTDA (E) and $\mathrm{NaOH}(\mathbf{F})$ extractions, in comparison to the non-treated control $(n=7$ independent curvature sections, error bars represent SEM). Two-way ANOVA followed by Tukey's test. Similar letters in the graphs mark no significant statistical difference. Different letters in the graphs mark significant statistical difference with a $p$-value $<0.05$.

On these samples, we performed comprehensive microarray polymer profiling (CoMPP) [32,33], using specific antibodies against different cell wall epitopes [34] (Figure S2A,B). We followed established protocols employing a calcium chelator cyclohexanediaminetetraacetic acid (CDTA) to extract the calcium-linked pectin matrix and to liberate the soluble cell wall fraction. Subsequently, we utilized $4 \mathrm{M} \mathrm{NaOH}$ to solubilize hydrogen-bonded hemicelluloses, including $\mathrm{XyG}$, and other more tightly bound cell wall components [32,33]. Notably, the LM15 monoclonal antibody $(\mathrm{mAb})$, generated against non-galactosylated and non-fucosylated xyloglucan fragments with the XXXG motif [35], displayed a notable gravity-induced asymmetry when used against $\mathrm{NaOH}$ extracts. In comparison, two other hemicellulose epitopes, such as xylan (LM10 mAb) and 
mannan (LM21 mAb) (Figure 1A-C), as well as other cell wall epitopes (Figure S2A,B) did not show such a defined differential distribution. This finding is in agreement with earlier studies, which suggested that auxin affects the solubility/properties of XyGs [36,37]. To assess if the altered galactosylation status of $\mathrm{XyG}$ indeed relates to auxin-induced differential elongation, we used local application of auxin (lanolin paste) to pea stems, causing the stem to bend (Figure 1D). In agreement with our gravity experiment, asymmetric application of auxin also induced changes in the abundance of LM15 epitopes at the site of application (Figure 1E,F). This set of data suggests that auxin-mediated growth is associated with less substituted XyGs in pea stems.

The detected changes in a CoMPP abundance could hint at spatial alterations in XyG structure or may alternatively relate to altered extractability of $\mathrm{XyG}$ moieties. Therefore, we studied the spatial distribution of $\mathrm{XyG}$ in situ using immunolocalization procedures (Figure 2) In addition to LM15, we also used the mAb CCRC-M1, which is specific for $\alpha$-L-fucosylated xyloglucan. Auxin application induced a more intense LM15 antibody labeling in the convex site, when compared to the concave side of the stem (Figure 2B,D and Figure S3A,B). Conversely, CCRC-M1 mAb labeling showed lower signal in the convex side in comparison to the concave side (Figure 2C,D and Figure S3A,B). In agreement, we also observed a similar, gravity induced asymmetry of CCRC-M1 labeling in dark grown Arabidopsis hypocotyls (Figure S4A,B). This set of data suggests that auxin induced cell expansion correlates with spatially defined changes in the molecular structure of XyGs.
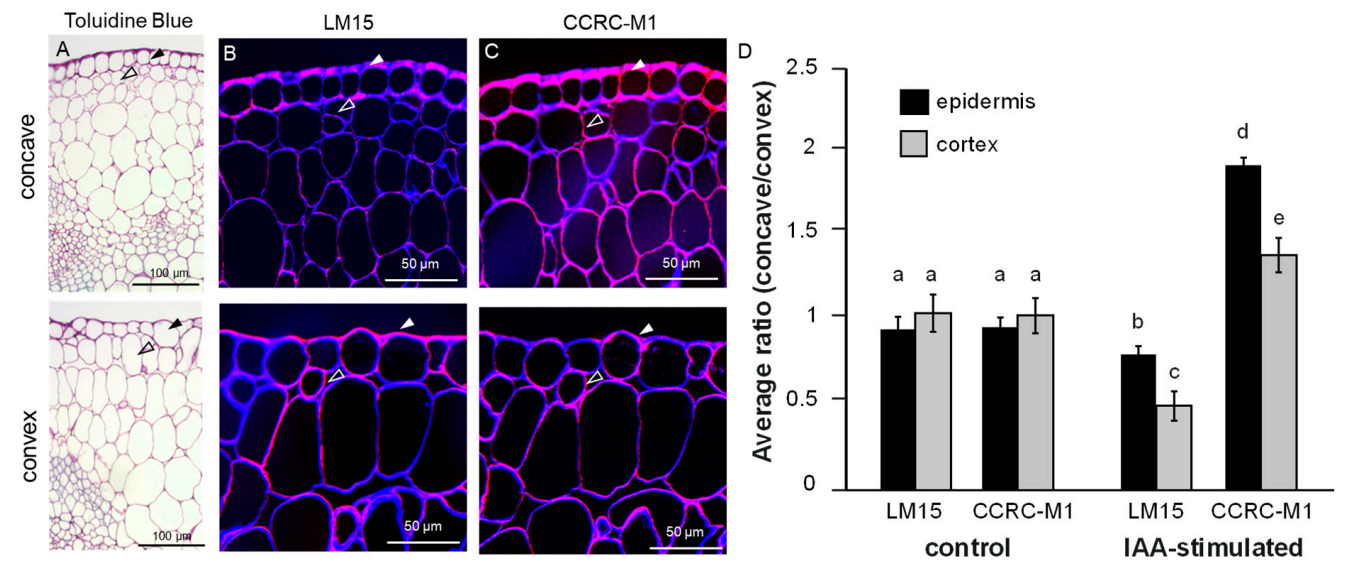

Figure 2. (A-D) In situ spatial distribution $\mathrm{XyG}$ in pea sections. (A) Toluidine staining of the thin resin section through auxin-modulated pea segment. Close up pictures on the tissue morphology of the concave (shorter) and the convex (longer, auxin-modulated). Note the enlargement of the epidermal (closed arrowhead) and cortical cells (open arrowhead) in the convex site. (B-D) Immunolocalization of LM15 (B) and CCRC-M1 (C) epitopes in concave (upper panels) and convex (lower panels) sides of the auxin paste-modulated stem. Images are overlays of the monoclonal antibodies (mAb)-generated signal (red) and the cell wall counterstaining with $\beta$-(1,4)-glucan-specific dye Calcofluor White (blue). Note the decrease of CCRC-M1 signal, but significant increase of the LM15 signal in the epidermis and cortex of the convex side. Closed arrowhead: epidermis; open arrowhead: cortex. (D) Quantification of the LM15 and CCRC-M1-generated signal ratios between the concave and convex side of the indole-3-acetic acid (IAA)-stimulated stem. Signals of epidermis and cortex were analyzed separately. Two sides of the control stem (lanolin only) showed no statistically significant differences in LM15 and CCRCM1 labeling $(n>26)$, One-way ANOVA with Tukey's post-hoc test with $p<0.05$. Error bars represent SEM. Similar letters in the graphs mark no significant statistical difference. Different letters in the graphs mark significant statistical difference with a $p$-value $<0.05$.

\subsection{Auxin Signaling Defines Complexity of XyG Structures}

Next, we genetically repressed nuclear auxin signaling by overexpressing PIN-LIKES (PILS) proteins in Arabidopsis. PILS proteins are endoplasmic reticulum (ER) localized auxin transport facilitators that repress nuclear abundance and signaling of auxin, presumably by 
reducing auxin diffusion into the nucleus $[5,6,38,39]$. The overexpression of PILS5 reduces auxin signaling and reduces growth in dark grown hypocotyls [5], which correlated with moderate alterations to the monosaccharide composition of wall preparations, showing slightly increased galactose as well as mildly decreased levels of rhamnose and xylose in dark grown hypocotyls (Figure S5A). Alterations in galactose levels may primarily relate to changes in Arabinogalactan proteins (AGPs) and/or pectic polysaccharides, such as galactans, but could also hint at alterations in $\mathrm{XyG}$ structure [40]. To specifically investigate the effect of auxin signaling depletion on $\mathrm{XyG}$ structure, we next used endoglucanase to generate $\mathrm{XyG}$ fragments to be analyzed via oligosaccharide mass profiling (OLIMP) by MALDI-TOF/MS [41] and most prominently observed an increase in fucosylation of XyGs in PILS5 overexpressing lines when compared to Wt (Figure S5B), independently confirming that low auxin signaling rates induce complex XyG structures in Arabidopsis.

Altogether, the combined approaches of CoMPP, immunocytochemistry and OLIMP revealed that auxin signaling indeed adjusts $\mathrm{XyG}$ structure, possibly providing spatially defined readouts.

\subsection{Genetic Modification of XyGs Define Auxin-Dependent Differential Growth}

In order to assess whether these structural alterations indeed define auxin-mediated differential growth, we genetically interfered with $\mathrm{XyG}$ complexity by targeting the genes encoding for fucosyltransferase MURUS2 (MUR2) and the fucosidase altered xyloglucan8 $(A X Y 8)$ as well as with the galactosyltransferase $M U R 3$ and the beta-glactosidase 10 (bGAL10) in Arabidopsis. Initially, we exogenously exposed mur2 and axy8 as well as mur3 and bgal10 dark grown mutants to auxin (Figures S6A-I and S7A,B). Galactosylation of $\mathrm{XyGs}$ appears to have a more pronounced effect on auxin-reliant growth than fucosylation, because hypocotyl expansion of bgal10, but not axy 8 mutants, was partially resistant to high exogenous levels of auxin (Figure S7A,B). In agreement, genetic crosses with bgal10 mutants partially alleviated the overexpression phenotype of auxin-biosynthesis enzyme YUCCA8 (YUC8) (Figure S7C-F). Moreover, we noted that mur3 mutant alleles displayed an amplified loss of gravitropic growth when exposed to exogenous auxin (Figure S6A,C,D,F). The curved mur3 dark grown hypocotyl phenotype was reminiscent to seedlings exposed to high levels of auxin (Figure S7A). Accordingly, the mur3 mutants might display some hypersensitivity to auxin, but on the other hand, the auxin induced repression of hypocotyl expansion was not enhanced when compared to Wt seedlings (Figure S6A,B,D,E). However, this relative assessment could be biased due to the already short hypocotyl phenotype of untreated mur3 mutants (Figure S6A,B,D,E).

In order to evaluate the importance of XyGs complexity for an endogenous auxin response, we examined the gravitropic responses in these XyG-related mutants. The mur3 alleles and mur2-1 mutant hypocotyls showed gravitropic defects when challenged with a $90^{\circ}$ angle change in growth orientation (Figure 3A,B and Figure S8A,B). However, compared to mur3-3 and mur3-7, gravitropic growth of mur2-1 mutants was markedly less affected. The expression of pMUR3:MUR3-mScarlet in mur3-3 alleviated the growth reduction and complemented the gravitropic defects (Figure S9A-E), additionally confirming that MUR3 has a defining role in gravitropic hypocotyl growth. On the other hand, axy8 and bgal10 mutants were not distinguishable from wild type seedlings in this gravitropic end point measurement experiment (Figure 3A,B). To further asses this phenotype in detail, we performed infrared-based growth kinetics measurements of gravitropic dark grown hypocotyls. We observed a hyper-bending response of mur3 mutants (Figure 3C), which relates to enhanced differential cellular elongation rates at the upper and lower hypocotyl flanks (Figure 3E,F). Accordingly, we conclude that the auxin-dependent, gravity-induced growth is accelerated in mur3 mutants. Conversely to the hyperbending phenotype of mur3, the growth kinetics of bgal10-1 mutants initially showed slower gravitropic bending when compared to $\mathrm{Wt}$ (Figure 3D), which also agrees with its partial resistance to auxin (Figure S7A-F). 

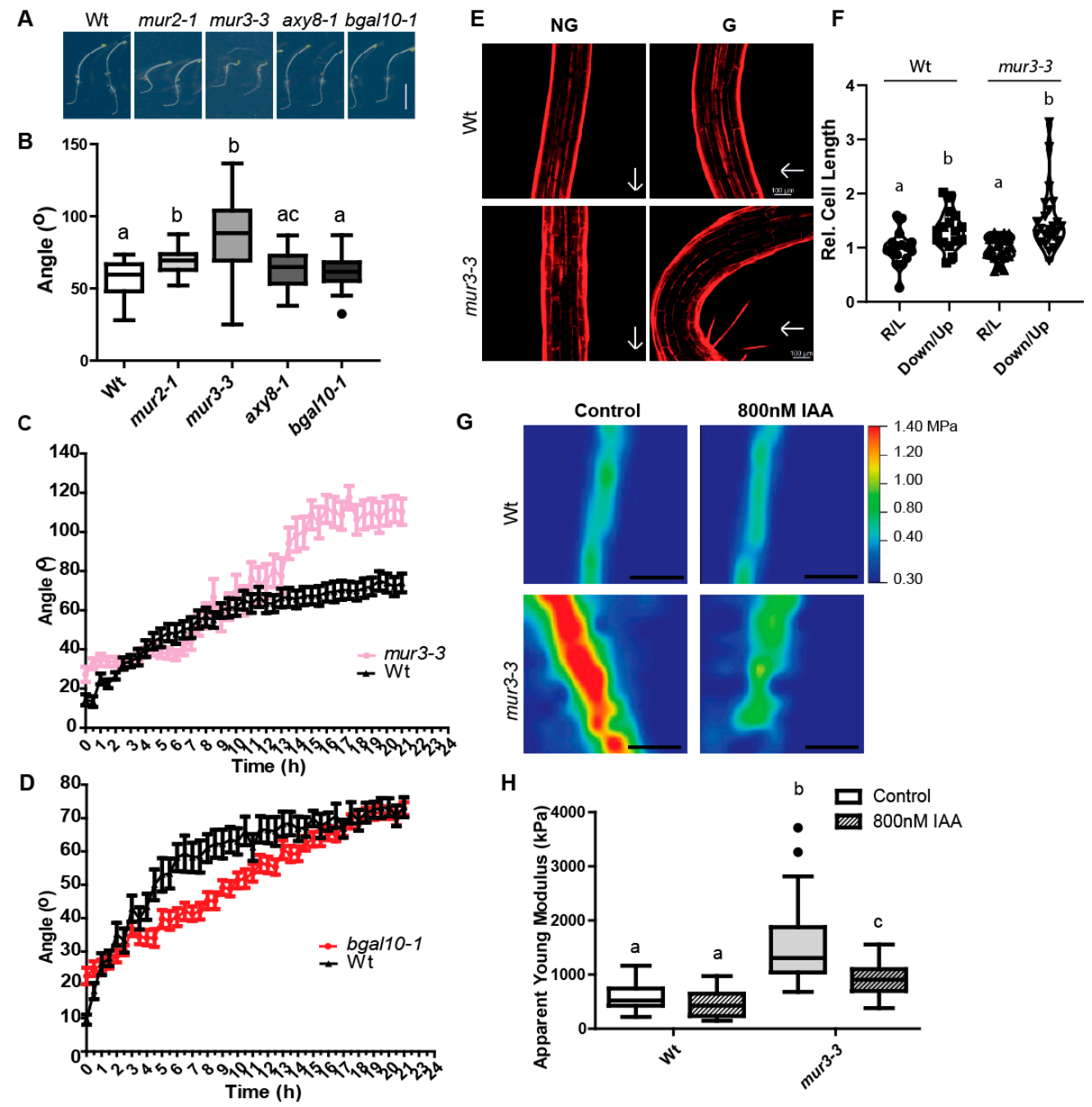

H

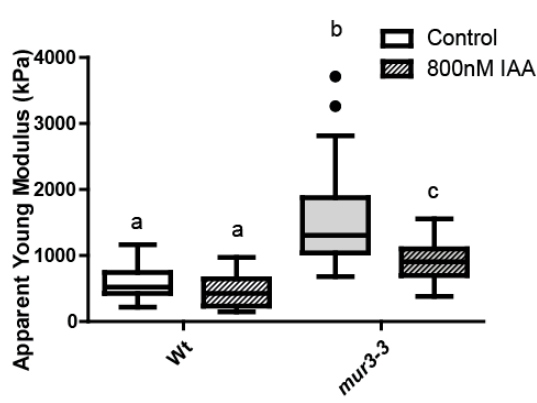

Figure 3. Response to gravistimulation of murus2-1 (mur2-1), murus3-3 (mur3-3), altered xyloglucan8 (axy8-1) and betagalactosidase10-1 (bgal10-1). (A,B) Five-day-old dark-grown hypocotyls were challenged with a $90^{\circ}$ angle change in growth orientation and the end point angle between the apex of the hypocotyl and gravity vector was measured $24 \mathrm{~h}$ later. (A) Representative images of the angular hypocotyl growth after $24 \mathrm{~h}$. (B) Quantification of the end point angle. Tukey box-plot. One-way ANOVA followed by Tukey's test. $p$-value $<0.05$. Scale bar $=5 \mathrm{~mm}(n=3$ biological replicates with $20-30$ angle measurements each). (C,D) Growth kinetics of mur3-3 (C) and bgal10-1. (D) Five-day-old dark-grown hypocotyls were challenged with a $90^{\circ}$ angle change in growth orientation and placed in an infrared-based dark-imaging box where their growth was recorded. The angle reached every $30 \mathrm{~min}$ was quantified. Non-linear fit to a one-phase association curve. $\mathrm{K}$ values for each curve were compared. $p$-value $<0.05$. Data are mean $\pm \operatorname{SEM}(n=3$ biological replicates with $12-28$ seedlings each). (E,F) Cell elongation of Wt and mur3-3 after gravistimulation. Five-day old etiolated hypocotyls were challenged with a $90^{\circ}$ angle change in orientation and left overnight, and then stained with propidium iodide. (E) Representative images. Scale bar $=100 \mu \mathrm{m}$. (F) Quantification of relative cell length. Between 2-3 cells from the cortex region were measured on the right (R) side and left (L) side of non-gravistimulated (NG) hypocotyls, or from the downwards side (Down) or upwards side (Up) of gravistimulated $(\mathrm{G})$ hypocotyls. The average of relative cell length between right and left (R/L), and down and up (Down/Up) is reported. Data are mean $\pm \mathrm{SD}(n=3$ biological replicates of cell length ratios corresponding to 20-22 seedlings). Kruskal-Wallis one-way ANOVA followed by Dunnett's test; $p$-value $<0.05$. (G,H) Atomic force microscopy (AFM) analysis of mur3-3. Dark-grown hypocotyls of mur3-3 and Wt Col-0 were grown for three days on 800 nM indole-3-acetic acid (IAA) or dimethyl sulfoxide [DMSO, (Control)]. (G) Representative apparent Young's modulus heat maps of one cell wall region perpendicular to the indentation axis and parallel to the growth axis (periclinal cell wall). Scale bar $=5 \mu \mathrm{m}$. $(\mathbf{H})$ Quantification of apparent Young's modulus in kilopascal (kPa). Tukey box-plot. One-Way ANOVA followed by Tukey's test; $p$-value $<0.05$ ( $n=3$ biological replicates with 30-40 AFM scans). Similar letters in the graphs mark no significant statistical difference. Different letters in the graphs mark significant statistical difference with a $p$-value $<0.05$. 
A family of xylosyltransferases (XXT) are responsible for the bulk of the xylosylation of the glucan backbone (Figure S1). Accordingly, XyGs are not detectable in $x x t 1 x x t 2$ mutants [42], which also correlated with defects in gravitropic hypocotyl growth (Figure S10A-E). When compared to the loss of the fucosylation machinery or even the complete lack of XyGs (Figure S10A-E), the MUR3/bGAL10 dependent galactosylation of XyGs appears to have a particular developmental importance for auxin-dependent gravitropic hypocotyl growth.

Altogether, these results show that genetic modification of XyG complexity distinctly defines auxin-dependent differential growth rates during gravitropic hypocotyl growth.

\subsection{MUR3 Defines the Auxin Effect on Cell Wall Mechanics}

Our results suggest that auxin defines the decorations of $\mathrm{XyG}$ sidechains and that this fine-tuning takes place in a spatially restricted manner, contributing to differential growth control. It is currently unknown how precisely the alterations in $\mathrm{XyG}$ structure impact on cell wall mechanical properties. To further assess the contribution of MUR3 to local cell wall mechanics, we used atomic force microscopy (AFM) to quantify cell wall properties in epidermal hypocotyl cells of full knockout mutant alleles, such as mur3-3 and mur3-7 [43]. The apparent Young's modulus obtained for Wt dark grown hypocotyl agreed with the previous published data [44-46]. However, the cell walls of untreated dark grown mur3-3 and mur3-7 mutant hypocotyls were much stiffer when compared to Wt (Figure 3G,H and Figure S8C,D). This observation correlates with an overall reduction in cell size and hypocotyl growth in mur3 mutants (Figure 3E,F and Figure S6A,B,D,E).

Notably, exogenously applied auxin [indole-3-acetic acid (IAA), $800 \mathrm{Nm}$ ] induced a stronger softening of mur3-3 and mur3-7 mutant cell walls when compared to Wt (Figure 3G,H and Figure S8C,D). Accordingly, we conclude that MUR3 defines the auxin impact on wall mechanics, which also agrees with the enhanced gravitropic growth of mur3 mutants. On the other hand, the here observed softening of mur3 mutant cell walls was not sufficient to induce organ growth (Figure S6A,B,D,E), suggesting additional growth inhibitory effects when auxin is exogenously applied.

\subsection{The Growth Mechanism Defines the Complexity of XyGs}

Next, we aimed to investigate whether relative changes in auxin abundance or the auxin-reliant growth programs define the complexity of XyGs. When seedlings are grown in darkness, cotyledon-derived auxin stimulates rapid hypocotyl elongation, while suboptimal auxin levels (whether increased or decreased) reduce its expansion [9,47]. For that purpose, we used constructs for estradiol-inducible auxin-biosynthesis enzyme YUCCA6 (YUC6) [48] and auxin-conjugating enzyme GRETCHEN-HAGEN3.6 (GH3.6) [49]. In agreement, estradiol-induced overexpression of YUC6 or GH3.6 have distinct effects on nuclear auxin signaling output markers, such as AUXIN/INDOLE-3-ACETIC19 (IAA19) and SMALL AUXIN UP RNA77 (SAUR77) (Figure S11A). However, both lines inhibited hypocotyl expansion when transferred to estradiol containing plates (Figure $4 \mathrm{~A}-\mathrm{D}$ ).

Already after $3 \mathrm{~h}$ of induction, YUC6 increased endogenous IAA levels in dark grown hypocotyls (Figure S11B). On the other hand, only a mild, statistically non-significant, reduction in auxin levels was detected after short term GH3.6 induction (Figure S11B). In order to further assess the biological activity of the lines, we subjected both lines to RNA sequencing. Compared to the empty vector control, we found 2177 and 1909 differentially expressed genes (DEG) after $3 \mathrm{~h}$ induction of YUC6 and GH3.6, respectively (Dataset S1). The overlapping genes clustered in four categories, displaying (I) up- or (II) downregulation in both as well as (III) up- and down- or (IV) down- and up- in YUC6 and GH3.6 induced dark grown hypocotyls, respectively (Figure S11C,D; Dataset S1). We identified 102 genes that showed inverse (category III and IV) regulation after induced YUC6 and GH3.6 overexpression. The gene ontology (GO)-term analysis (Dataset S2) of these DEGs (Dataset S1) showed enrichment for auxin- and cell wall-related pathways, confirming the distinct molecular effects of YUC6 and GH3.6 induction on auxin signaling in dark grown hypocotyls. Furthermore, we observed a reproducible, but rather mild upregulation of the 
MUR3 transcript after YUC6 induction (Figure S12A,B). In agreement, we also detected an up-regulation of MUR3-mScarlet protein levels upon an exogenous application of auxin (Figure S12C,D). Accordingly, a transcriptional input of auxin signaling could contribute to the regulation of XyGs. In agreement, the ectopic induction of auxin biosynthesis enzyme YUC6 and the auxin amido synthetase GH3.6 have in part opposing effects on the transcription of XyG biosynthesis genes (Figure S12A).

A

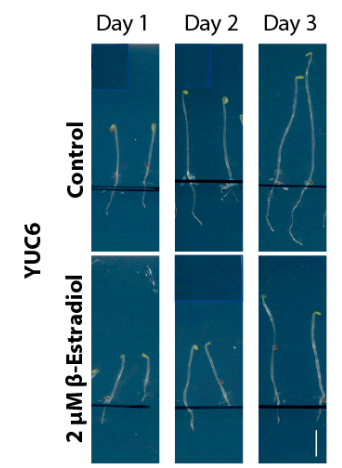

C

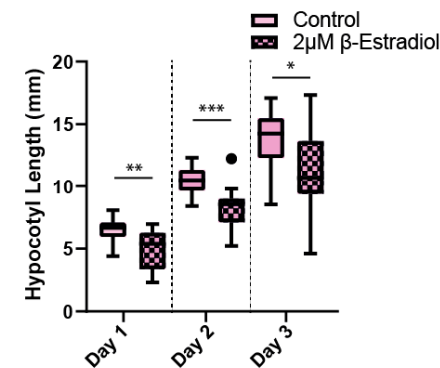

E

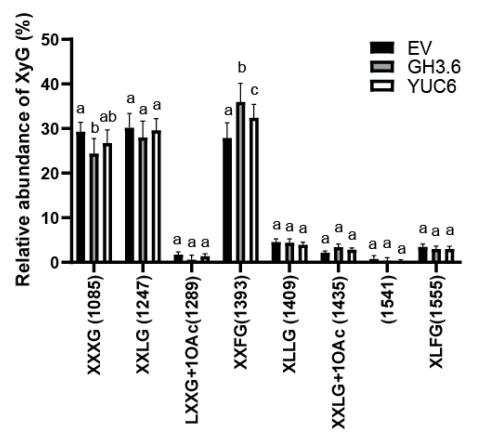

B
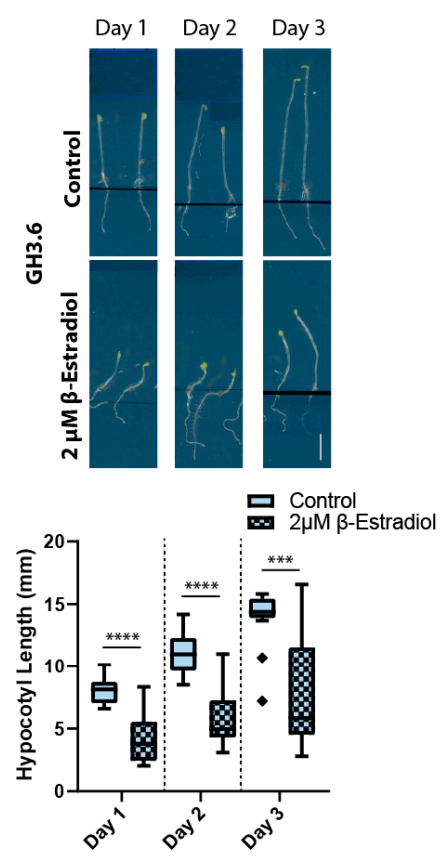

F

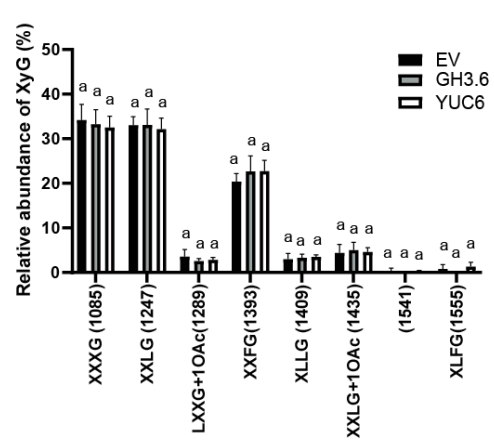

Figure 4. (A-D) Hypocotyl growth phenotype of estradiol inducible YUCCA6 (YUC6), GRETCHENHAGEN3.6 (GH3.6) and empty vector control (EV). Three-day-old seedlings were transferred onto 2 $\mu \mathrm{M}$ estradiol or control plates and left for one, two or three days. (A,B) Representative images of YUC6 (A), GH3.6 (B) on control media or estradiol-containing media after one, two or three days of induction. Scale bar $=$ five $\mathrm{mm}$. Please note that distracting labels on the scanned plate were removed by covering them with blue boxes (outlined by light blue lines). (C,D) Quantification of hypocotyl length (mean \pm SD) of YUC6 (C) and GH3.6 (D). $t$-test with $p$-value $<0.05$. ( $n=3$ biological replicates with 5-10 seedlings each). (E,F) Oligosaccharide mass profiling (OLIMP) on upper (growing part) (E) and lower (non-growing part). (F) sections of hypocotyls of inducible GH3.6, YUC6 and empty vector control (EV). All lines were induced for three hours with $10 \mu \mathrm{M}$ B-estradiol. Data are mean \pm $\mathrm{SD}\left(n=4\right.$ biological replicates). *: $p$-value $\leq 0.05,{ }^{* *}: p$-value $\leq 0.01,{ }^{* * *}: p$-value $\leq 0.001,{ }^{* * * *}: p$-value $\leq 0.0001$. Similar letters in the graphs mark no significant statistical difference. Different letters in the graphs mark significant statistical difference with a $p$-value $<0.05$. XyG: Xyloglucan. $\mathrm{XyG}$ sidechains 'nomenclature: G (Glucose), X (Glucose + Xylose), L (Glucose + Xylose + Galactose), $F$ (Glucose + Xylose + Galactose + Fucose), Ac: Acetyl group. 
Next, we made use of the distinct molecular, but overlapping effects of YUC6 and GH3.6 on hypocotyl growth and addressed whether adjustments in cellular auxin levels or the auxin-mediated growth context may correlate with alteration in XyG branching. Performing OLIMP after short term $(3 \mathrm{~h})$ application of estradiol, we observed YUC6and GH3.6-induced increase in fucosylation of XyGs in the upper, expanding part of dark grown hypocotyls when compared to empty vector controls (Figure 4E). On the other hand, the lower part of the dark grown hypocotyls, which is not actively growing or shows at least strongly reduced expansion rates [50,51], did not display the YUC6 and GH3-induced fucosylation of XyGs (Figure 4F).

Accordingly, we conclude that rather than the relative change in auxin abundance, it is the underlying growth program that defines the complexity of XyGs.

\section{Discussion}

Based on our set of data, we propose that auxin signaling output and its underlying growth programs define XyG backbone substitution. We moreover propose that higher and lower structural complexity of XyG contribute to repression and induction of tissue expansion, respectively (Figure S13). Considering that MUR3 modulates the auxin effect on cell wall mechanics, we hypothesize that spatially restricted impact on XyG composition contributes to cell wall mechanics for differential growth.

It needs to be seen how precisely auxin-related growth programs molecularly define XyG structure. Notably, our RNAseq data hinted at a transcriptional input of auxin signaling. The induction of YUC6 and GH3.6 initiate opposing transcriptional effects, but both cause overlapping effects on XyG structure and plant growth. Accordingly, we assume that transcriptional auxin responses cannot fully recapitulate the observed molecular alterations. It is hence likely that indirect and/or posttranslational mechanisms also contribute to the modifications of XyGs. Phosphorylation of CELLULOSE SYNTHASE A (CESA) is a known regulation of cellulose biosynthesis [52,53]. Considering the ultrafast auxin-mediated protein phosphorylation response [54] a similar post-translational regulation could be envisioned to directly or indirectly impact on XyG-related enzymes.

Besides the mechanical contribution to cell expansion, the cell wall composition in turn is also sensed and provides a feedback signaling to cellular functions [55]. In apical hooks, $x x t 1 \quad x x t 2$ deficiency exerts a negative feedback on the transcription of auxin transport components, abolishing auxin maxima formation and, hence, differential growth [21]. In contrast to apical hook development, we did not find evidences that this feedback mechanism disrupts asymmetric hypocotyl expansion. In contrast to apical hooks, auxinreliant differential growth in gravitropic hypocotyls is on the contrary enhanced in $x x t 1$ $x x t 2$ deficient mutants. These insights suggest a distinct, tissue-specific mode of action for growth control in apical hooks and during gravitropic hypocotyl growth. This is also reminiscent to tissue specific auxin perception mechanisms, because hypocotyl expansion requires canonical TIR1/AFBs transcriptional responses [9], but TMK1-mediated, nongenomic auxin responses contribute to growth repression in apical hooks [11]. On the other hand, AUXIN SIGNALING F-BOX 1 (AFB1) also defines fast, non-transcriptional responses [56].

It remains to be seen how precisely the XyG structure contributes to auxin-reliant wall mechanics for differential growth control in gravitropic hypocotyls. Tissue biophysical measurements using AFM did not show altered mechanical properties in shoot apical meristems of $x x t 1 x x t 2$ mutants when compared to $\mathrm{Wt}$, which is likely due to compensatory mechanisms in this tissue [57]. Our AFM data set shows on the contrary that mur3 knock out mutants display stiffer cell walls. On the other hand, a close to $50 \%$ reduction in tensile strength was detected for hypocotyls of a partial loss-of-function allele mur3-1 in which MUR3 protein level is reduced [58]. The time-dependent extension analysis (tensile strength) relates to longitudinal forces along an entire organ and hence may not strictly correlate with AFM-indentation-based cellular measurements in the epidermis. These two 
methods may even show the contribution of different cell wall polymers to distinct cell wall parameters [59].

Alterations in XyG structure presumably affect the hydrogen bonding of XyGs with cellulose microfibrils and/or other cell wall polymers, affecting its $\mathrm{pH}$-dependent interactions $[60,61]$. Accordingly, the interaction of XyGs with other cell wall components may also relate to the observed differences in AFM and tensile strength analysis of mur3 mutants [58]. In agreement with a complex interaction of distinct cell wall components, arabinoxylans and pectins can compensate for the mechanical load in XyG-deficient mutants [62]. In addition, the CELLULOSE SYNTHASE-like C (CSLC) proteins contribute to XyG biosynthesis, because the quintuple cslc456812 mutant completely lacks detectable XyGs and phenocopies the $x x t 1$ xxt2 double mutant [63].

MUR3-dependent galactosylation appears to have particular importance for plant development [64], but in this context it is largely unknown how the galactosylation status of XyGs impact its interactions with other cell wall components. Here we show that MUR3-dependent galactosylation is also most decisive for its impact on auxin-related growth. However, the absence of detectable XyGs (as seen in $x x+1 x x+2$ double mutants) also modulates auxin related growth processes, but to a weaker extent. The ectopic O-acetylation of XyGs in Arabidopsis alters xylosylation pattern and impairs plant growth $[65,66]$, illustrating the importance of backbone modifications. Our work provides further mechanistic insight into the side chain decoration of XyGs, suggesting that the auxin-mediated, spatial alterations in XyG structure could locally impact on the complex cell wall mechanics, allowing for differential tensions and growth along the organ.

\section{Materials and Methods}

\subsection{Plant Material}

The Wt background for all lines described is Col-0. Lines murus2-1 (mur2-1; AT2G03220) [67], altered xylogucan8 (axy8-1; AT4G34260) [68], murus 3-3 (mur3-3; AT2G20370; Salk_141953) and murus3-7 (mur3-7; Salk_127057) [43], and beta-galactosidase10-1 (bgal10-1) [69] have been previously described. The axy8-1 line was courtesy of Markus Pauly, mur3-3 and mur3-7 were courtesy of Malcom O'Neill, and bgal 10-1 was courtesy of Ignacio Zarra. All seeds can be obtained from the Arabidopsis Biological Resource Center (https:/ /abrc.osu.edu/; Columbus, OH, USA). The 35s:PILS5-GFP (PILS5 ${ }^{\mathrm{OE}}$ ) line was described in Barbez et al. 2012 [5]. Primers used for genotyping are listed on Table S1.

\subsection{Growth Conditions}

Seeds were sterilized overnight with chlorine gas, and afterwards plated in $0.8 \%$ agar, $0.5 \times$ Murashige and Skoog (MS), and 1\% sucrose medium (MS+). For the majority of the experiments (unless stated otherwise), the plates containing the seeds were stratified for two days at $4{ }^{\circ} \mathrm{C}$, and then exposed to cool-white light $\left(140 \mu \mathrm{mol} \cdot \mathrm{m}^{-2} \cdot \mathrm{s}^{-1}\right)$ for $6-8 \mathrm{~h}$ at $21^{\circ} \mathrm{C}$ so as to induce germination and subsequently kept in the dark for five days at $21^{\circ} \mathrm{C}$.

For the auxin treatment experiments, the MS medium was supplemented with $800 \mathrm{nM}$ indole-3-acetic acid (IAA) or less than $0.1 \%$ DMSO. The seedlings were placed on this medium and grown as described above.

\subsection{RNA Extraction and RT-qPCR Analysis}

We always used hypocotyl tissue for RNA extractions. For the estradiol-induced assays, a $100 \mu \mathrm{m}$ pore mesh (Mesh Nitex 03-100/44; VWR, Avantor, Vienna, Austria) was placed on top the MS+ medium, and then the seeds were placed on top of this mesh. The plates were then handled as described above for three days (estradiol treatments). At day three, the plates were uncovered under a green light, so as not to activate any light responses, and the mesh was transferred onto a new plate containing $10 \mu \mathrm{M} \beta$-estradiol, and then kept in the dark for three hours (estradiol), respectively. Tissue was harvested afterwards and total RNA was isolated using the InnuPREP Plant RNA Kit (Analytic Jena), following the manufacturer's instructions. After RNA extraction, samples were treated 
with InnuPREP DNase I (Analytic Jena). cDNA was synthesized from $1 \mu \mathrm{g}$ of RNA using the iSCRIPT cDNA synthesis Kit (Bio-Rad) following manufacturer's recommendations. We used Takyon qPCR Kit for SYBR assay (Eurogentec) and the RT-PCR was carried out in CFX96 Touch Real-Time PCR Detection System (Bio-Rad). ACT2 (AT3G18780) was used as housekeeping [70,71] unless stated otherwise. For RNAseq validations, gene AT1G29670 was used as housekeeping, since it was a gene that was stable for all lines and treatments. This gene was selected from the RNAseq data. Primers for all tested genes are listed in Table S1.

\subsection{Cloning}

Gateway cloning was used to construct $p M D C 7 \_B(p U B Q): G H 3.6$. The GRETCHENHAGEN3.6 (GH3.6) full-length genomic fragment was amplified by PCR from genomic DNA. Primers are listed in Table S1. The PCR was performed using the high-fidelity DNA polymerase "I proof" (Bio-Rad). The full genomic fragments were cloned into the pDONR221 (Invitrogen) vector using Invitrogen BP-clonase according to manufacturer's instructions. Coding sequences were transferred from the entry clones to gateway-compatible pMDC7_B(pUBQ) vector [5] using the Invitrogen LR clonase according to manufacturer's instructions. The resulting construct as well as an empty vector were transformed into Col-0 plants by floral dipping in Agrobacterium tumefaciens GV3101 strain liquid cultures.

Gateway cloning was used to construct pMUR3:MUR3-mScarlet. A 1474 bp intergenic region upstream of the starting codon of the MURUS3 (MUR3) gene was used as the promoter for MUR3. This region was amplified from genomic DNA via PCR using the Q5 NEB high-fidelity polymerase following the manufacturer's instructions. Primers used are listed in the Table S1. The fragment was cloned on a pJET 1.2 blunt cloning vector following manufacturer's instructions (Thermo Fisher, Vienna, Austria). The BsaI restriction site present in the fragment was mutated from ggtctc to ggcctc. The full-length genomic MUR3 fragment was amplified by PCR from genomic DNA with the NEB Q5 high-fidelity polymerase, and subsequently cloned into a pJET 1.2 blunt cloning vector. Primers are listed in the Table S1. The final Goldengate assembly was made in the pGGZ003 destination vector following the protocol described by Lampropoulos et al. [72]. All the other required modules for the assembly were obtained from Addgene (Addgene kit \#1000000036) [72]. The resulting construct pMUR3:MUR3-mScarlet was transformed into Wt Col-0 plants following the floral dipping method and selected on MS+ BASTA plates.

The mur3-3/pMUR3:MUR3-mScarlet complementation line was obtained by crossing.

\subsection{Quantification of Hypocotyl Length and Gravity Index}

Seedlings were grown for five days in the dark on vertically orientated plates. After this, the plates were scanned with an Epson Perfection V700 scanner. Hypocotyl length was quantified using FIJI 2.0 software [73].

The Gravity index was calculated as described by [74], where the index is defined as the average cosine of the angle between the gravity vector and the direction of the hypocotyl elongation.

For the ß-Estradiol inducible lines pER8:YUCCA6 [75], pMDC7::GH3.6 and pMDC7 empty vector control (EV), the seeds were first plated onto meshes as described above and after three days, these meshes were transferred onto an MS+ plate containing either dimethyl sulfoxide [DMSO, (control)] or $2 \mu \mathrm{M}$ ß-Estradiol, and then left for 1, 2 and 3 days. Afterwards, the plates were scanned and the hypocotyl length was measured as detailed above.

\subsection{Gravi-Stimulation Assays and Quantification}

Seedlings were grown for four days and then turned $90^{\circ}$ and kept in this position for another $24 \mathrm{~h}$. Afterwards, plates were scanned with an Epson Perfection V700 scanner. We measured the angle that was formed between the apex of the hypocotyl and the gravity vector, using the angle tool of the FIJI software. 
For the assay where the seedlings were afterwards stained with propidium iodide (PI), the gravistimulation was overnight.

\subsection{Real Time Analysis of Gravitropic Response}

Seedlings were grown for four days and then turned $90^{\circ}$ then placed in this new position in light-sealed box equipped with an infrared light source (880 $\mathrm{nm}$ LED) and a spectrum-enhanced camera (EOS035 Canon Rebel T3i) [6]. The angles made between the hypocotyl apex and the gravity vector were measured every $30 \mathrm{~min}$ with the angle tool of FIJI. Representative experiments are shown. Gravitropism kinetics were statistically analyzed using a non-linear regression fit to a one-phase association curve [6].

\subsection{Confocal Imaging and Quantification}

Imaging was performed using a Leica TCS SP5 confocal microscope, equipped with HyD detector. The fluorescence signal intensity (Mean Gray Value) was quantified using the LEICA LAS AF Lite software. In all cases, a Region of Interest (ROI) was defined, and the signal intensity was quantified within that region. The same ROI was kept for all analyzed images within said experiment. ROIs used are indicated in the respective figures. Excitation and emission peaks for $\mathrm{mScarlet}$ are $561 \mathrm{~nm}$ and $607 \mathrm{~nm}$, respectively; and $569 \mathrm{~nm}$ and $593 \mathrm{~nm}$ for PI.

When PI was used, seedlings were incubated for $30 \mathrm{~min}($ mur3-3), and $1 \mathrm{~h}(\mathrm{Wt})$ in a PI solution of $0.02 \mathrm{mg} / \mathrm{mL}$.

\subsection{RNA-Seq}

Three-day old seedlings of pMDC7:GH3.6, pER8::YUC6 [75] and pMDC7 empty vector lines were grown and induced as already described above. After the induction time, hypocotyl tissue was harvested and total RNA was extracted using the RNAeasy Plant Mini Kit (Qiagen) following manufacturer's instructions. Prior to cDNA synthesis, RNA was treated with the RNase-Free DNase Set (Qiagen) with the manufacturer's recommendations.

The RNA libraries and the subsequent sequencing were performed by the Next Generation Sequencing Facility from the Vienna Biocenter (https:/ / www.viennabiocenter.org/ vbcf/next-generation-sequencing/; accessed 16 March 2018)The libraries were generated with the NEBNext Ultra II RNA Library Prep Kit for Illumina with poly(A) enrichment. The sequencing was performed on an Illumina HiSeq2500 with $250 \mathrm{bp}$ paired ended fragments.

\subsection{Bioinformatics Analysis of the RNAseq Data}

4.10.1. Data Pre-Processing

Ribosomal RNA reads were removed by mapping the raw reads against the ribosomal transcript sequences using bwa mem [0.7.16a-r1181, [76]]. The paired end reads were extracted from the unmapped reads using bedtools bamToFastq (v2.29.0, [77]) and the Illumina TruSeq adapters were trimmed with cutadapt [78].

\subsubsection{Differential Gene Expression Analysis}

To determine differential gene expression in the pER8:YUC6 [75] and pMDC7:GH3.6 seedlings compared to the $\mathrm{pMDC7}$ empty vector plant line, we considered the transcript per million (TPM) values estimated with Salmon [v0.9.1, [79]] for the AtRTD2-QUASI transcriptome annotation [80], and used tximport [81] to aggregate the transcript read counts per gene. Differentially expressed genes were obtained with edgeR using the exactTest [82]. Genes were considered differentially expressed for a false discovery rate $<0.05$.

\subsubsection{GO-Term Analysis}

GO-term analysis was performed using the PANTHER Overrepresentation Test (Released 2019.07.11) at http:/ /www.pantherdb.org/ (accessed on 3 December 2018). The 
enrichment was determined comparing the query list of differentially expressed genes with an $A$. thaliana database using a FISHER test with an FDR $<0.05$.

\subsection{Auxin Measurements}

Determination of indole-3-acetic acid (IAA) metabolite levels was performed following the methods described before [83]. As tissue, five-day-old dark-grown hypocotyls of pER8:YUC6 [75], pMDC7::GH3.6 and pMDC7 empty vector control (EV) lines, induced for $3 \mathrm{~h}$ on $2 \mu \mathrm{M} \beta$-Estradiol were used. Briefly, $10 \mathrm{mg}$ of tissue were extracted with $1 \mathrm{~mL}$ of $50 \mathrm{mM}$ phosphate buffer ( $\mathrm{pH} 7.0$ ) containing $0.1 \%$ sodium diethyldithiocarbamate and mixture of stable isotope-labeled auxins standards. A $200 \mu \mathrm{L}$ portion of each extract was acidified with $1 \mathrm{M} \mathrm{HCl}$ to $\mathrm{pH} 2.7$ and purified by in-tip micro solid phase extraction. After evaporation under reduced pressure, samples were analyzed using HPLC system 1260 Infinity II (Agilent Technologies, Santa Clara, CA, USA) equipped with Kinetex C18 column (50 mm $\times 2.1 \mathrm{~mm}, 1.7 \mu \mathrm{m}$; Phenomenex, Torrance, CA, USA). The LC system was linked to 6495 Triple Quad detector (Agilent Technologies, Santa Clara, CA, USA). All samples were measured in quadruplicate for each genotype.

\subsection{Atomic Force Measurements and Apparent Young's Modulus Calculations}

The AFM data were collected and analyzed as described elsewhere with minor changes [44]. To examine extracellular matrix properties, we suppressed turgor pressure by immersion of the seedlings in a hypertonic solution (10\% mannitol) for at least 20 min before examination. Three-day-old seedlings grown in darkness (in normal AM plate, with or without IAA) were placed in microscopy slides and immobilized using double-glued side tape. We focused on the periclinal cell walls (parallel to growth axis, but perpendicular to the organ surface), and its extracellular matrix. To ensure proper indentations, especially on the regions in the bottom of the dome shape between two adjacent cells, we used cantilevers with long pyramidal tips (14-16 $\mu \mathrm{m}$ of pyramidal height, AppNano ACST-10), with a spring constant of $7.8 \mathrm{~N} / \mathrm{m}$. The instrument used was a JPK Nano-Wizard 4.0 and indentations were kept to $<10 \%$ of cell height (typically indentations of $100-200 \mathrm{~nm}$ depth and $500 \mathrm{nN}$ force). Three scan-maps per sample were taken over an intermediate region of the hypocotyls, using a square area of $25 \times 25 \mu \mathrm{m}$, with $16 \times 16$ measurements, resulting in 1792 force-indentation experiments per sample. The lateral deflection of the cantilever was monitored and in case of any abnormal increase the entire data set was not used for analysis. The apparent Young's modulus (EA) for each force-indentation experiment was calculated using the approach curve (to avoid any adhesion interference) with the JPK Data Processing software (JPK Instruments AG, Berlin, Germany), based on the Hertz model adjusted to pyramidal tip geometry. To calculate the average EA for each periclinal wall, the EA was measured over the total length of the extracellular region using masks with Gwyddion 2.45 software (at least 20 points were taken in account). The pixels corresponding to the extracellular matrix were chosen based on the topography map. For topographical reconstructions, the height of each point was determined by the point-of-contact from the force-indentation curve. A total of 12-14 samples were analyzed. A standard t-test was applied to test for differences between genotypes.

\subsection{Monosaccharide Composition Analysis}

The analysis was performed using four-day-old dark grown hypocotyls on MS half strength supplemented with sucrose. Two grams of this tissue were used to prepare alcohol-insoluble material to be used in the later analysis. For this purpose, hypocotyls were washed twice in four volumes of absolute ethanol for $15 \mathrm{~min}$, then rinsed twice in four volumes of acetone at room temperature for $10 \mathrm{~min}$ and left to dry under a fume hood overnight at room temperature. For determining the neutral monosaccharide composition, $10 \mathrm{mg}$ of dried alcohol-insoluble material were hydrolyzed in $2.5 \mathrm{M}$ trifluoroacetic acid for $1 \mathrm{~h}$ at $100{ }^{\circ} \mathrm{C}$ as described by [84]. The released Glucose was diluted 500 times and 
subsequently quantified by means of High Performance Anion Exchange Chromatographypulsed amperometric detection (HPAEC-PAD) chromatography.

\subsection{Xyloglucan Fingerprinting (Oligosaccharide Mass Profiling (OLIMP))}

Using a green light, five-day old dark-grown seedlings were collected and stored in cold ethanol. Four hypocotyls were dissected for each biological repeat $(n=4)$, and later used for the analysis. After being left overnight at room temperature in ethanol, the ethanol was removed and the hypocotyls were dried at $37^{\circ} \mathrm{C}$ for $1 \mathrm{~h}$. Afterwards, $20 \mu \mathrm{L}$ of $50 \mathrm{mM}$ acetate buffer, $\mathrm{pH} 5.0$, containing endoglucanase from Trichoderma longibrachiatum (Megazyme, Scotland, UK) were added and left overnight at $37^{\circ} \mathrm{C}$. OLIMP was then carried out as described elsewhere [41] using Super 2,5-dihydroxybenzoic acid (DHB) matrix (9:1 mixture of DHB and 2-hydroxy-5-methoxybenzoic acid; Fluka) instead of DHB. A solution of the $\mathrm{XyG}$ fragments after endoglucanase treatment was used to obtain the Matrix assisted laser desorption ionization-time of flight (MALDI-TOF) spectra.

For the pMDC7:GH3.6, pER8:YUC6 and pMDC7 empty vector control (EV), the hypocotyls were grown in the dark for five days on top of $100 \mu \mathrm{m}$ pore mesh MS+ plates and then the meshes were transferred to $2 \mu \mathrm{M} \beta$-estradiol MS+ plates. The hypocotyls were dissected into upper section and lower section for the analysis.

\subsection{Gravi-Stimulation and Auxin-Induced Bending Experiments on Pea}

Pisum sativum L. cv. Kelvedon Wonder seeds (Frøbutikken, Denmark) were sterilized with hypochlorite solution before germination on wet tissue in a sterilized plastic box in the dark at room temperature for five days. Seedlings with 3-4 $\mathrm{cm}$ roots were transferred to soil (Pindstrup Mosebrug A/S, Ryomgaard, Denmark). Plants were grown at $22^{\circ} \mathrm{C} / 20^{\circ} \mathrm{C}$ under $16 \mathrm{~h} / 8 \mathrm{~h}$ day $/$ night temperature cycle in growth chambers under fluorescent light $\left(200 \mu \mathrm{mol} \mathrm{m} \mathrm{m}^{-2} \mathrm{~s}^{-1}\right)$ for one week. Plants were laid down horizontally for one week. Curved stems were harvested and dissected longitudinally to separately obtain the longer (more elongated) and shorter (less elongated) sides. Stems at the same internode of the plant growing vertically were collected as control. Fresh samples were weighed and homogenized by TissueLyser (Sigma-Aldrich, Søborg, Denmark) using a metal bead at max speed. Eight sample pairs were used in the Comprehensive Microarray Polymer Profiling (CoMPP) study.

For the auxin-induced bending experiments, pea plants were planted as described above for the gravistimulation experiment. The tops of three-week-old pea plants were removed down to the second internode from the tip. Lanolin paste containing Indole-3acetic acid (IAA, Sigma-Aldrich, Søborg, Denmark) (10 mg of IAA per $1 \mathrm{~g}$ of lanolin) was applied to one side of the second internode. Stems treated with unadulterated lanolin paste were set as controls. Curved or straight stems were harvested after three days of treatment. The three-day period was chosen because it allowed for the full formation of the curvature and the shorter and longer side could be reliably separated. The stems were dissected longitudinally to separate the longer and shorter sides. A set of three stems was used in CoMPP study.

\subsection{Comprehensive Microarray Polymer Profiling (CoMPP)}

CoMPP analysis was carried out as previously described [32]. Tissuelyzed fresh samples were placed in two solvents sequentially, $50 \mathrm{mM}$ cyclohexanediaminetetraacetic acid (CDTA) and $4 \mathrm{M} \mathrm{NaOH}$ with $1 \%(v / v) \mathrm{NaBH}_{4}$ at $30: 1(\mu \mathrm{L} / \mathrm{mg})$. After two hours extraction by shaking and $1700 \mathrm{rcf}$ centrifugation, supernatants were printed onto a nitrocellulose membrane in four printing replicates and four dilutions in ratios of 1:2, 1:6, 1:18 and 1:54 $(v / v)$. The microarray was probed with a range of cell wall component-directed monoclonal antibodies (mAbs) [34] and the intensity of binding was quantified by implementing an individual scaling. 


\subsection{LR Resin Embedding and Sectioning}

For Arabidopsis experiments, hypocotyl sections of two-day-old seedlings were fixed in $4 \%$ paraformaldehyde (PFA) in phosphate buffered saline (PBS) for $45 \mathrm{~min}$ afterward washed 4 times with PBS buffer. Samples were dehydrated for 30 min sequentially at $30 \%, 50 \%, 70 \%, 90 \%$ and $100 \% \mathrm{EtOH}$ in PBS. LR white was added to samples dropwise to $10 \%$ and incubated at $4{ }^{\circ} \mathrm{C}$ for $6 \mathrm{~h}$. Afterwards, the solution was exchanged with $30 \% \mathrm{LR}$ white in PBS and incubated at $4{ }^{\circ} \mathrm{C}$ overnight. The solution was subsequently exchanged with $100 \%$ LR white 3 times each with $12 \mathrm{~h}$ incubation and polymerized at $60{ }^{\circ} \mathrm{C}$ for $36 \mathrm{~h}$. Samples were sectioned at $2.5 \mu \mathrm{M}$ thickness using a Reichert Ultracut S Wild M3Z microtome mounted with a Diatome Histo Diamond Knife $\left(8.0 \mathrm{~mm} 45^{\circ}\right.$ angle). Sections were placed on glass slides.

For the pea experiments, the auxin stimulated and control segments of approximately $1 \mathrm{~cm}$ of size were fixed in formaldehyde (prepared from 4\% paraformaldehyde in PBS by heating). The samples were washed twice with PBS and dehydrated trough ethanol series (30\%, 50\%, 70\%, 96\% and absolute ethanol). The LR embedding was performed by incubating the samples first in the 1:1 mixture of LR resin:absolute ethanol (Sigma-Aldrich, Søborg, Denmark) overnight and then in pure resin LR resin overnight. The samples were place to gelatin capsule filled with LR resin, oriented and polymerized in a heat oven at $60{ }^{\circ} \mathrm{C}$ overnight. The gelatin capsule was removed, blocks were trimmed and sectioned using Leica ultramicrotome to $1 \mu \mathrm{m}$-thick sections which were collected on water drops on charged SuperFrost slides and let to adhere at a heat plate set at $60^{\circ} \mathrm{C}$.

\subsection{Histological Staining, Immunolocalization and Microscopy}

For the Arabidopsis sections, immunolabeling was performed on sections using CCRCM1 primary antibody raised in mouse (Agrisera, Vännäs, Sweden) [85] with 1:100 dilution with PBS buffer. Secondary antibody anti Cy5 (Jacksson Immunoresearch) was used with dilution of 1:200. Images were taken using Carl Zeiss LSM780 using 40× magnification (Zeiss C-Apochromat 40×/1.2W Corr M27). Cy5 was excited at $633 \mathrm{nM}$.

For the pea sections, the overall morphology was studied using staining with $1 \%$ Toluidine Blue in water for approximately $5 \mathrm{~min}$. After washing the sections twice with water, the sections were observed under light microscope Olympus BX41 and the pictures were recorded with the digital camera. For immunolocalization, the circular regions surrounding the adhered sections were marked with PapPen (Agar Scientific, Vedbaek, Denmark). The sections were blocked with approximately $100 \mu \mathrm{L}$ of the $5 \%$ milk powder/PBS, followed by a $1 \mathrm{~h}$ incubation with the mixture of CCRC-M1 and LM15 primary antibody in the blocking solution at 1:10 dilution each. After washing three times with PBS, incubation with the mixture of anti-rat or anti-mouse secondary antibody conjugated to AlexaFluor 555 or Alexafluor 488, respectively, diluted at 1:300 in 5\% milk powder/PBS (Thermo Fisher, Roskilde, Denmark), washing twice with PBS, incubation for 10 min with Calcofluor White (Merc, $100 \mu \mathrm{g} / \mathrm{mL}$ final concentration) and one time washing with PBS. The sections were finally mounted in Citifluor (Agar Scientific, Vedbaek, Denmark) and covered with a coverslip.

The observation was done immediately. The Leica SP5 laser-scanning confocal microscope and LAS X software were used for the acquiring of the subsequent images. The Argon laser $(488 \mathrm{~nm}$ ) was used for the excitation of AlexaFluor488 signal and the HeliumNeon $(555 \mathrm{~nm})$ laser was used for the excitation of the AlexaFluor555 signal and $405 \mathrm{~nm}$ diode for the Calcofluor White signal. The specificity of the labeling signal was compared to control sections labeled with the mixture of secondary antibodies only. The pictures were processed with GIMP2 software to generate overlays and to adjust brightness and contrast. If not indicated otherwise the reagents and chemicals were purchased from (Sigma-Aldrich, Søborg, Denmark). The signal intensity was quantified using ImageJ software and the statistical difference was assessed by one-way ANOVA. 


\subsection{Data Analysis}

All graphs and statistical analysis were made with GraphPad Prism software, versions 5 and 8 . Statistical tests are depicted in the figure legends. All experiments were performed at least three times.

Supplementary Materials: The following are available online at https:/ /www.mdpi.com/article/10 $.3390 /$ ijms22179222/s1.

Author Contributions: Conceptualization, S.M.V. and J.K.-V.; Data Curation, P.V. and M.K.; Formal Analysis, S.M.V., M.G., B.A., M.D., A.P. and G.M.; Funding Acquisition, M.K., G.M., E.B., R.P.B., J.M. and J.K.-V.; Investigation, S.M.V., X.G., M.G., B.A., E.B. (Elke Barbez), K.A.D., M.D., A.P., G.M. and J.M.; Project Administration, S.M.V. and J.K.-V.; Resources, O.N., G.M., E.B. (Eva Benková), R.P.B., J.M. and J.K.-V.; Supervision, M.K., E.B. (Eva Benková), R.P.B., J.M. and J.K.-V.; Validation, J.M.; Visualization, S.M.V., M.G., B.A., M.D. and A.P.; Writing-Original Draft, S.M.V. and J.K.-V.; Writing-Review and Editing, S.M.V., M.G., M.D., O.N., M.K., J.M. and J.K.-V. All authors have read and agreed to the published version of the manuscript.

Funding: This work was supported by the Villum Foundation grant 00017489 (J.M.), Vienna Science and Technology Fund (WWTF) (to J.K.-V.), European Research Council (AuxinER-ERC starting grant 639478 to J.K.-V.), the Austrian Science Fund (FWF) (grant number P26333 to M.K.; P26591 to J.K.-V.), and the Ministry of Education, Youth and Sports of the Czech Republic through the European Regional Development Fund-Project (CZ.02.1.01/0.0/0.0/16_019/0000827 to A.P. and O.N.).

Institutional Review Board Statement: Not applicable.

Data Availability Statement: Project accession number is PRJNA721549. NCBI SRA accession numbers are SRR14226357-SRR14226365.

Acknowledgments: We are grateful to Paul Knox, Markus Pauly, Malcom O’Neill, and Ignacio Zarra for providing published material; the BOKU-VIBT Imaging Center for access and M. Debreczeny for expertise; J.I. Thaker and Georg Seifert for critical reading.

Conflicts of Interest: The authors declare no conflict of interest.

\section{References}

1. Sauer, M.; Robert, S.; Kleine-Vehn, J. Auxin: Simply complicated. J. Exp. Bot. 2013, 64, 2565-2577. [CrossRef]

2. Rosquete, M.R.; Barbez, E.; Kleine-Vehn, J. Cellular auxin homeostasis: Gatekeeping is housekeeping. Mol. Plant 2012, 5, 772-786. [CrossRef]

3. Sauer, M.; Kleine-Vehn, J. PIN-FORMED and PIN-LIKES auxin transport facilitators. Development 2019, 146, dev168088. [CrossRef]

4. Gallei, M.; Luschnig, C.; Friml, J. Auxin signalling in growth: Schrödinger's cat out of the bag. Curr. Opin. Plant Biol. 2020, 53, 43-49. [CrossRef]

5. Barbez, E.; Kubeš, M.; Rolčík, J.; Béziat, C.; Pěnčík, A.; Wang, B.; Rosquete, M.R.; Zhu, J.; Dobrev, P.I.; Lee, Y. A novel putative auxin carrier family regulates intracellular auxin homeostasis in plants. Nature 2012, 485, 119-122. [CrossRef]

6. Béziat, C.; Barbez, E.; Feraru, M.I.; Lucyshyn, D.; Kleine-Vehn, J. Light triggers PILS-dependent reduction in nuclear auxin signalling for growth transition. Nat. Plants 2017, 3, 17105. [CrossRef]

7. Calderón Villalobos, L.I.A.; Lee, S.; De Oliveira, C.; Ivetac, A.; Brandt, W.; Armitage, L.; Sheard, L.B.; Tan, X.; Parry, G.; Mao, H.; et al. A combinatorial TIR1/AFB-Aux/IAA co-receptor system for differential sensing of auxin. Nat. Chem. Biol. 2012, 8, 477-485. [CrossRef] [PubMed]

8. Dharmasiri, N.; Dharmasiri, S.; Weijers, D.; Lechner, E.; Yamada, M.; Hobbie, L.; Ehrismann, J.S.; Jürgens, G.; Estelle, M. Plant development is regulated by a family of auxin receptor F box proteins. Dev. Cell 2005, 9, 109-119. [CrossRef] [PubMed]

9. Fendrych, M.; Leung, J.; Friml, J. TIR1/AFB-Aux/IAA auxin perception mediates rapid cell wall acidification and growth of Arabidopsis hypocotyls. Elife 2016, 5, e19048. [CrossRef] [PubMed]

10. Fendrych, M.; Akhmanova, M.; Merrin, J.; Glanc, M.; Hagihara, S.; Takahashi, K.; Uchida, N.; Torii, K.U.; Friml, J. Rapid and reversible root growth inhibition by TIR1 auxin signalling. Nat. Plants 2018, 4, 453. [CrossRef] [PubMed]

11. Cao, M.; Chen, R.; Li, P.; Yu, Y.; Zheng, R.; Ge, D.; Zheng, W.; Wang, X.; Gu, Y.; Gelová, Z. TMK1-mediated auxin signalling regulates differential growth of the apical hook. Nature 2019, 568, 240-243. [CrossRef]

12. Dai, N.; Wang, W.; Patterson, S.E.; Bleecker, A.B. The TMK subfamily of receptor-like kinases in Arabidopsis display an essential role in growth and a reduced sensitivity to auxin. PLoS ONE 2013, 8, e60990. [CrossRef] [PubMed]

13. Majda, M.; Robert, S. The role of auxin in cell wall expansion. Int. J. Mol. Sci. 2018, 19, 951. [CrossRef]

14. Lampugnani, E.R.; Khan, G.A.; Somssich, M.; Persson, S. Building a plant cell wall at a glance. J. Cell Sci. 2018, 131, jcs207373. [CrossRef] [PubMed] 
15. Pauly, M.; Keegstra, K. Biosynthesis of Plant Cell wall matrix polysaccharide xyloglucan. Annu. Rev. Plant Biol. 2016, 67, 235-259. [CrossRef]

16. Schultink, A.; Liu, L.; Zhu, L.; Pauly, M. Structural diversity and function of xyloglucan sidechain substituents. Plants 2014, 3, 526-542. [CrossRef]

17. Hager, A.; Menzel, H.; Krauss, A. Experiments and hypothesis concerning the primary action of auxin in elongation growth. Planta 1971, 100, 47-75. [CrossRef] [PubMed]

18. Dünser, K.; Kleine-Vehn, J. Differential growth regulation in plants-the acid growth balloon theory. Curr. Opin. Plant Biol. 2015, 28, 55-59. [CrossRef]

19. Cosgrove, D.J. Re-constructing our models of cellulose and primary cell wall assembly. Curr. Opin. Plant Biol. 2014, 22, 122-131. [CrossRef]

20. Barbez, E.; Dünser, K.; Gaidora, A.; Lendl, T.; Busch, W. Auxin steers root cell expansion via apoplastic pH regulation in Arabidopsis thaliana. Proc. Natl. Acad. Sci. USA 2017, 114, E4884-E4893. [CrossRef]

21. Aryal, B.; Jonsson, K.; Baral, A.; Sancho-Andres, G.; Routier- Kierzkowska, A.-L.; Kierzkowski, D.; Bhalerao, R.P. Interplay between Cell Wall and Auxin Mediates the Control of Differential Cell Elongation during Apical Hook Development. Curr. Biol. 2020, 30, 1733-1739. [CrossRef]

22. Abel, S.; Oeller, P.W.; Theologis, A. Early auxin-induced genes encode short-lived nuclear proteins. Proc. Natl. Acad. Sci. USA 1994, 91, 326-330. [CrossRef]

23. Catalá, C.; Rose, J.K.; Bennett, A.B. Auxin regulation and spatial localization of an endo- 1 , 4- $\beta$-d-glucanase and a xyloglucan endotransglycosylase in expanding tomato hypocotyls. Plant J. 1997, 12, 417-426. [CrossRef]

24. Catalá, C.; Rose, J.K.; York, W.S.; Albersheim, P.; Darvill, A.G.; Bennett, A.B. Characterization of a tomato xyloglucan endotransglycosylase gene that is down-regulated by auxin in etiolated hypocotyls. Plant Physiol. 2001, 127, 1180-1192. [CrossRef]

25. Osato, Y.; Yokoyama, R.; Nishitani, K. A principal role for AtXTH18 in Arabidopsis thaliana root growth: A functional analysis using RNAi plants. J. Plant Res. 2006, 119, 153-162. [CrossRef]

26. Sánchez, M.; Gianzo, C.; Sampedro, J.; Revilla, G.; Zarra, I. Changes in $\alpha$-xylosidase during intact and auxin-induced growth of pine hypocotyls. Plant Cell Physiol. 2003, 44, 132-138. [CrossRef] [PubMed]

27. Talbott, L.D.; Ray, P.M. Changes in Molecular Size of Previously Deposited and Newly Synthesized Pea Cell Wall Matrix Polysaccharides. Eff. Auxin Turgor 1992, 98, 369-379. [CrossRef] [PubMed]

28. Vissenberg, K.; Oyama, M.; Osato, Y.; Yokoyama, R.; Verbelen, J.-P.; Nishitani, K. Differential expression of AtXTH17, AtXTH18, AtXTH19 and AtXTH20 genes in Arabidopsis roots. Physiological roles in specification in cell wall construction. Plant Cell Physiol. 2005, 46, 192-200. [CrossRef]

29. Xu, W.; Purugganan, M.M.; Polisensky, D.H.; Antosiewicz, D.M.; Fry, S.C.; Braam, J. Arabidopsis TCH4, regulated by hormones and the environment, encodes a xyloglucan endotransglycosylase. Plant Cell 1995, 7, 1555-1567. [PubMed]

30. York, W.S.; Darvill, A.G.; Albersheim, P. Inhibition of 2, 4-dichlorophenoxyacetic acid-stimulated elongation of pea stem segments by a xyloglucan oligosaccharide. Plant Physiol. 1984, 75, 295-297. [CrossRef] [PubMed]

31. Rakusová, H.; Gallego-Bartolomé, J.; Vanstraelen, M.; Robert, H.S.; Alabadí, D.; Blázquez, M.A.; Benková, E.; Friml, J. Polarization of PIN3-dependent auxin transport for hypocotyl gravitropic response in Arabidopsis thaliana. Plant J. 2011, 67, 817-826. [CrossRef] [PubMed]

32. Moller, I.; Sørensen, I.; Bernal, A.J.; Blaukopf, C.; Lee, K.; Øbro, J.; Pettolino, F.; Roberts, A.; Mikkelsen, J.D.; Knox, J.P. Highthroughput mapping of cell-wall polymers within and between plants using novel microarrays. Plant J. 2007, 50, 1118-1128. [CrossRef]

33. Kračun, S.K.; Fangel, J.U.; Rydahl, M.G.; Pedersen, H.L.; Vidal-Melgosa, S.; Willats, W.G.T. Carbohydrate microarray technology applied to high-throughput mapping of plant cell wall glycans using comprehensive microarray polymer profiling (CoMPP). In High-Throughput Glycomics and Glycoproteomics; Springer: Berlin/Heidelberg, Germany, 2017; pp. 147-165.

34. Rydahl, M.G.; Hansen, A.R.; Kračun, S.K.; Mravec, J. Report on the current inventory of the toolbox for plant cell wall analysis: Proteinaceous and small molecular probes. Front. Plant Sci. 2018, 9, 581. [CrossRef] [PubMed]

35. Ruprecht, C.; Bartetzko, M.P.; Senf, D.; Dallabernadina, P.; Boos, I.; Andersen, M.C.; Kotake, T.; Knox, J.P.; Hahn, M.G.; Clausen, M.H. A synthetic glycan microarray enables epitope mapping of plant cell wall glycan-directed antibodies. Plant Physiol. 2017, 175, 1094-1104. [CrossRef] [PubMed]

36. Labavitch, J.M.; Ray, P.M. Turnover of cell wall polysaccharides in elongating pea stem segments. Plant Physiol. 1974, 53, 669-673. [CrossRef]

37. Nishitani, K.; Masuda, Y. Auxin-induced changes in the cell wall xyloglucans: Effects of auxin on the two different subtractions of xyloglucans in the epicotyl cell wall of Vigna angularis. Plant Cell Physiol. 1983, 24, 345-355.

38. Feraru, E.; Feraru, M.I.; Barbez, E.; Waidmann, S.; Sun, L.; Gaidora, A.; Kleine-Vehn, J. PILS6 is a temperature-sensitive regulator of nuclear auxin input and organ growth in Arabidopsis thaliana. Proc. Natl. Acad. Sci. USA 2019, 116, 3893-3898. [CrossRef]

39. Sun, L.; Feraru, E.; Feraru, M.I.; Waidmann, S.; Wang, W.; Passaia, G.; Wang, Z.-Y.; Wabnik, K.; Kleine-Vehn, J. PIN-LIKES coordinate brassinosteroid signaling with nuclear auxin input in Arabidopsis thaliana. Curr. Biol. 2020, 30, 1579-1588. [CrossRef]

40. Nguema-Ona, E.; Andème-Onzighi, C.; Aboughe-Angone, S.; Bardor, M.; Ishii, T.; Lerouge, P.; Driouich, A. The reb1-1 Mutation of Arabidopsis. Effect on the Structure and Localization of Galactose-Containing Cell Wall Polysaccharides. Plant Physiol. 2006, 140, 1406-1417. [CrossRef] 
41. Lerouxel, O.; Choo, T.S.; Séveno, M.; Usadel, B.; Faye, L.C.; Lerouge, P.; Pauly, M. Rapid structural phenotyping of plant cell wall mutants by enzymatic oligosaccharide fingerprinting. Plant Physiol. 2002, 130, 1754-1763. [CrossRef]

42. Cavalier, D.M.; Lerouxel, O.; Neumetzler, L.; Yamauchi, K.; Reinecke, A.; Freshour, G.; Zabotina, O.A.; Hahn, M.G.; Burgert, I.; Pauly, M.; et al. Disrupting Two Arabidopsis thaliana Xylosyltransferase Genes Results in Plants Deficient in Xyloglucan, a Major Primary Cell Wall Component. Plant Cell 2008, 20, 1519-1537. [CrossRef] [PubMed]

43. Kong, Y.; Peña, M.J.; Renna, L.; Avci, U.; Pattathil, S.; Tuomivaara, S.T.; Li, X.; Reiter, W.-D.; Brandizzi, F.; Hahn, M.G.; et al. Galactose-Depleted Xyloglucan Is Dysfunctional and Leads to Dwarfism in Arabidopsis. Plant Physiol. 2015, 167, 1296-1306. [CrossRef] [PubMed]

44. Peaucelle, A.; Wightman, R.; Höfte, H. The Control of Growth Symmetry Breaking in the Arabidopsis Hypocotyl. Curr. Biol. 2015, 25, 1746-1752. [CrossRef]

45. Peaucelle, A.; Braybrook, S.A.; Le Guillou, L.; Bron, E.; Kuhlemeier, C.; Höfte, H. Pectin-induced changes in cell wall mechanics underlie organ initiation in Arabidopsis. Curr. Biol. 2011, 21, 1720-1726. [CrossRef] [PubMed]

46. Hurný, A.; Cuesta, C.; Cavallari, N.; Ötvös, K.; Duclercq, J.; Dokládal, L.; Montesinos, J.C.; Gallemí, M.; Semerádová, H.; Rauter, T. SYNERGISTIC ON AUXIN AND CYTOKININ 1 positively regulates growth and attenuates soil pathogen resistance. Nat. Commun. 2020, 11, 2170. [CrossRef] [PubMed]

47. Takahashi, K.; Hayashi, K.-I.; Kinoshita, T. Auxin activates the plasma membrane $\mathrm{H}^{+}$-ATPase by phosphorylation during hypocotyl elongation in Arabidopsis. Plant Physiol. 2012, 159, 632-641. [CrossRef]

48. Cheng, Y.; Dai, X.; Zhao, Y. Auxin biosynthesis by the YUCCA flavin monooxygenases controls the formation of floral organs and vascular tissues in Arabidopsis. Genes Dev. 2006, 20, 1790-1799. [CrossRef]

49. Staswick, P.E.; Serban, B.; Rowe, M.; Tiryaki, I.; Maldonado, M.T.; Maldonado, M.C.; Suza, W. Characterization of an Arabidopsis enzyme family that conjugates amino acids to indole-3-acetic acid. Plant Cell 2005, 17, 616-627. [CrossRef]

50. Bastien, R.; Legland, D.; Martin, M.; Fregosi, L.; Peaucelle, A.; Douady, S.; Moulia, B.; Höfte, H. KymoRod: A method for automated kinematic analysis of rod-shaped plant organs. Plant J. 2016, 88, 468-475. [CrossRef]

51. Gendreau, E.; Traas, J.; Desnos, T.; Grandjean, O.; Caboche, M.; Hofte, H. Cellular basis of hypocotyl growth in Arabidopsis thaliana. Plant Physiol. 1997, 114, 295-305. [CrossRef]

52. Speicher, T.L.; Li, P.Z.; Wallace, I.S. Phosphoregulation of Plant Cellulose Synthase Complex and Cellulose Synthase-Like Proteins. Plants 2018, 7, 52. [CrossRef] [PubMed]

53. Chen, S.; Ehrhardt, D.W.; Somerville, C.R. Mutations of cellulose synthase (CESA1) phosphorylation sites modulate anisotropic cell expansion and bidirectional mobility of cellulose synthase. Proc. Natl. Acad. Sci. USA 2010, 107, 17188-17193. [CrossRef]

54. Han, H.; Verstraeten, I.; Roosjen, M.; Mazur, E.; Rýdza, N.; Hajný, J.; Ötvös, K.; Weijers, D.; Friml, J. Rapid auxin-mediated phosphorylation of Myosin regulates trafficking and polarity in Arabidopsis. bioRxiv 2021. [CrossRef]

55. Vaahtera, L.; Schulz, J.; Hamann, T. Cell wall integrity maintenance during plant development and interaction with the environment. Nat. Plants 2019, 5, 924-932. [CrossRef] [PubMed]

56. Serre, N.B.C.; Kralík, D.; Yun, P.; Slouka, Z.; Shabala, S.; Fendrych, M. AFB1 controls rapid auxin signalling through membrane depolarization in Arabidopsis thaliana root. Nat. Plants 2021. [CrossRef]

57. Zhao, F.; Chen, W.-Q.; Sechet, J.; Martin, M.; Bovio, S.; Lionnet, C.; Long, Y.; Battu, V.; Mouille, G.; Monéger, F. Xyloglucans and microtubules synergistically maintain meristem geometry and phyllotaxis. Plant Physiol. 2019, 181, 1191-1206. [CrossRef] [PubMed]

58. Peña, M.J.; Ryden, P.; Madson, M.; Smith, A.C.; Carpita, N.C. The galactose residues of xyloglucan are essential to maintain mechanical strength of the primary cell walls in Arabidopsis during growth. Plant Physiol. 2004, 134, 443-451. [CrossRef]

59. Zhang, T.; Tang, H.; Vavylonis, D.; Cosgrove, D.J. Disentangling loosening from softening: Insights into primary cell wall structure. Plant J. 2019, 100, 1101-1117. [CrossRef] [PubMed]

60. Cosgrove, D.J. Plant cell wall extensibility: Connecting plant cell growth with cell wall structure, mechanics, and the action of wall-modifying enzymes. J. Exp. Bot. 2015, 67, 463-476. [CrossRef]

61. Lima, D.U.; Loh, W.; Buckeridge, M.S. Xyloglucan-cellulose interaction depends on the sidechains and molecular weight of xyloglucan. Plant Physiol. Biochem. 2004, 42, 389-394. [CrossRef] [PubMed]

62. Park, Y.B.; Cosgrove, D.J. Changes in cell wall biomechanical properties in the xyloglucan-deficient xxt1/xxt2 mutant of Arabidopsis. Plant Physiol. 2012, 158, 465-475. [CrossRef] [PubMed]

63. Kim, S.-J.; Chandrasekar, B.; Rea, A.C.; Danhof, L.; Zemelis-Durfee, S.; Thrower, N.; Shepard, Z.S.; Pauly, M.; Brandizzi, F.; Keegstra, K. The synthesis of xyloglucan, an abundant plant cell wall polysaccharide, requires CSLC function. Proc. Natl. Acad. Sci. USA 2020, 117, 20316-20324. [CrossRef] [PubMed]

64. Jensen, J.K.; Schultink, A.; Keegstra, K.; Wilkerson, C.G.; Pauly, M. RNA-Seq Analysis of Developing Nasturtium Seeds (Tropaeolum majus): Identification and Characterization of an Additional Galactosyltransferase Involved in Xyloglucan Biosynthesis. Mol. Plant 2012, 5, 984-992. [CrossRef] [PubMed]

65. Zhong, R.; Cui, D.; Phillips, D.R.; Richardson, E.A.; Ye, Z.-H. A Group of O-Acetyltransferases Catalyze Xyloglucan Backbone Acetylation and Can Alter Xyloglucan Xylosylation Pattern and Plant Growth When Expressed in Arabidopsis. Plant Cell Physiol. 2020, 61, 1064-1079. [CrossRef]

66. Liu, L.; Hsia, M.M.; Dama, M.; Vogel, J.; Pauly, M. A xyloglucan backbone 6-O-acetyltransferase from Brachypodium distachyon modulates xyloglucan xylosylation. Mol. Plant 2016, 9, 615-617. [CrossRef] 
67. Vanzin, G.F.; Madson, M.; Carpita, N.C.; Raikhel, N.V.; Keegstra, K.; Reiter, W.-D. The mur2 mutant of Arabidopsis thaliana lacks fucosylated xyloglucan because of a lesion in fucosyltransferase AtFUT1. Proc. Natl. Acad. Sci. USA 2002, 99, 3340-3345. [CrossRef]

68. Günl, M.; Neumetzler, L.; Kraemer, F.; de Souza, A.; Schultink, A.; Pena, M.; York, W.S.; Pauly, M. AXY8 encodes an $\alpha$-fucosidase, underscoring the importance of apoplastic metabolism on the fine structure of Arabidopsis cell wall polysaccharides. Plant Cell 2011, 23, 4025-4040. [CrossRef]

69. Sampedro, J.; Gianzo, C.; Iglesias, N.; Guitián, E.; Revilla, G.; Zarra, I. AtBGAL10 is the main xyloglucan $\beta$-galactosidase in Arabidopsis, and its absence results in unusual xyloglucan subunits and growth defects. Plant Physiol. 2012, 158, 1146-1157. [CrossRef]

70. Ferrero, L.V.; Gastaldi, V.; Ariel, F.D.; Viola, I.L.; Gonzalez, D.H. Class I TCP proteins TCP14 and TCP15 are required for elongation and gene expression responses to auxin. Plant Mol. Biol. 2021, 105, 147-159. [CrossRef]

71. Zhu, J.; Geisler, M. Keeping it all together: Auxin-actin crosstalk in plant development. J. Exp. Bot. 2015, 66, 4983-4998. [CrossRef]

72. Lampropoulos, A.; Sutikovic, Z.; Wenzl, C.; Maegele, I.; Lohmann, J.U.; Forner, J. GreenGate-A novel, versatile, and efficient cloning system for plant transgenesis. PLoS ONE 2013, 8, e83043. [CrossRef] [PubMed]

73. Schindelin, J.; Arganda-Carreras, I.; Frise, E.; Kaynig, V.; Longair, M.; Pietzsch, T.; Preibisch, S.; Rueden, C.; Saalfeld, S.; Schmid, B. Fiji: An open-source platform for biological-image analysis. Nat. Methods 2012, 9, 676-682. [CrossRef]

74. Grabov, A.; Ashley, M.; Rigas, S.; Hatzopoulos, P.; Dolan, L.; Vicente-Agullo, F. Morphometric analysis of root shape. New Phytol. 2005, 165, 641-652. [CrossRef]

75. Mashiguchi, K.; Tanaka, K.; Sakai, T.; Sugawara, S.; Kawaide, H.; Natsume, M.; Hanada, A.; Yaeno, T.; Shirasu, K.; Yao, H. The main auxin biosynthesis pathway in Arabidopsis. Proc. Natl. Acad. Sci. USA 2011, 108, 18512-18517. [CrossRef] [PubMed]

76. Li, H. Aligning sequence reads, clone sequences and assembly contigs with BWA-MEM. arXiv 2013, arXiv:1303.3997.

77. Quinlan, A.R.; Hall, I.M. BEDTools: A flexible suite of utilities for comparing genomic features. Bioinformatics 2010, 26, 841-842. [CrossRef] [PubMed]

78. Martin, M. Cutadapt removes adapter sequences from high-throughput sequencing reads. EMBnet. J. 2011, 17, 10-12. [CrossRef]

79. Patro, R.; Duggal, G.; Love, M.I.; Irizarry, R.A.; Kingsford, C. Salmon provides fast and bias-aware quantification of transcript expression. Nat. Methods 2017, 14, 417. [CrossRef] [PubMed]

80. Zhang, R.; Calixto, C.P.; Marquez, Y.; Venhuizen, P.; Tzioutziou, N.A.; Guo, W.; Spensley, M.; Entizne, J.C.; Lewandowska, D.; Ten Have, S. A high quality Arabidopsis transcriptome for accurate transcript-level analysis of alternative splicing. Nucleic Acids Res. 2017, 45, 5061-5073. [CrossRef] [PubMed]

81. Soneson, C.; Love, M.I.; Robinson, M.D. Differential analyses for RNA-seq: Transcript-level estimates improve gene-level inferences. F1000Research 2015, 4. [CrossRef]

82. Robinson, M.D.; McCarthy, D.J.; Smyth, G.K. edgeR: A Bioconductor package for differential expression analysis of digital gene expression data. Bioinformatics 2010, 26, 139-140. [CrossRef]

83. Pěnčík, A.; Casanova-Sáez, R.; Pilařová, V.; Žukauskaitė, A.; Pinto, R.; Micol, J.L.; Ljung, K.; Novák, O. Ultra-rapid auxin metabolite profiling for high-throughput mutant screening in Arabidopsis. J. Exp. Bot. 2018, 69, 2569-2579. [CrossRef] [PubMed]

84. Harholt, J.; Jensen, J.K.; Sørensen, S.O.; Orfila, C.; Pauly, M.; Scheller, H.V. ARABINAN DEFICIENT 1 is a putative arabinosyltransferase involved in biosynthesis of pectic arabinan in Arabidopsis. Plant Physiol. 2006, 140, 49-58. [CrossRef] [PubMed]

85. Puhlmann, J.; Bucheli, E.; Swain, M.J.; Dunning, N.; Albersheim, P.; Darvill, A.G.; Hahn, M.G. Generation of Monoclonal Antibodies against Plant Cell-Wall Polysaccharides (I. Characterization of a Monoclonal Antibody to a Terminal [alpha]-(1-> 2)-Linked Fucosyl-Containing Epitope. Plant Physiol. 1994, 104, 699-710. [CrossRef] [PubMed] 